writing and rewriting over and over, and leaving your graduate students alone.

Perhaps the most interesting parts of the book are those that surround each paper or set of related papers. The forewords describe why they did each experiment. Then they describe what they did right and wrong, and comment a little (actually, very little) on subsequent developments in the field. Best of all, these parts, and the introductory chapters, are peppered with incidental remarks on how (and how not) to do science.

For example, on grants they say that much of their research "can be described as a massive fishing expedition, an expression commonly used by study sections to disparage bad grant requests". Their research, they explain, was seldom hypothesis driven. "But the lack of a hypothesis need not necessarily prevent one from catching big fish."

On computation: an example of the "illnesses" that can afflict science is an increase in "a theory sometimes called computation ... molecular biology, which we regard as more successful as a science than our field, seems largely to have avoided being beset with computation. In The Molecular Biology of the Gene I look in vain for equations."

On doing experiments, they write: "Unlike much of today's science, in which the actual work is done by technicians or graduate students ... it is we who get to do the experiments."

Hubel says he saves time by reading as little as possible in his field: "Reading most papers today is like eating sawdust.” He also says the pair benefited from their "refusal to waste time bothering with measuring intensities, rates of movement, and so on, or to spend time drawing graphs or histograms."

On statistics: "We could hardly get excited about an effect so feeble as to require statistics for its demonstration." And on failing to notice the directional properties of MT cells despite recording from about 200 of them: "We were lazy and not very bright."

There are two subjects on which I would have liked to see more. The first is their students: who were they, what did they work on, and how were they mentored? Perhaps they were just left alone. There is more about how Kuffler helped the duo than how they treated their own students.

The other subject is how the two collaborators actually worked together. One disagreement is obliquely referred to without explaining what it was. They speak of bulging files of 30 years of experimental protocols, a folder for each experiment. It would have been instructive to include some examples of these protocols, even if it meant fewer reprinted papers in the volume. But perhaps those files are for the historians, rather than an autobiographical volume.

Charles G. Gross is in the Department of Psychology, Princeton University, Green Hall,

Princeton, New Jersey 08544-1010, USA.

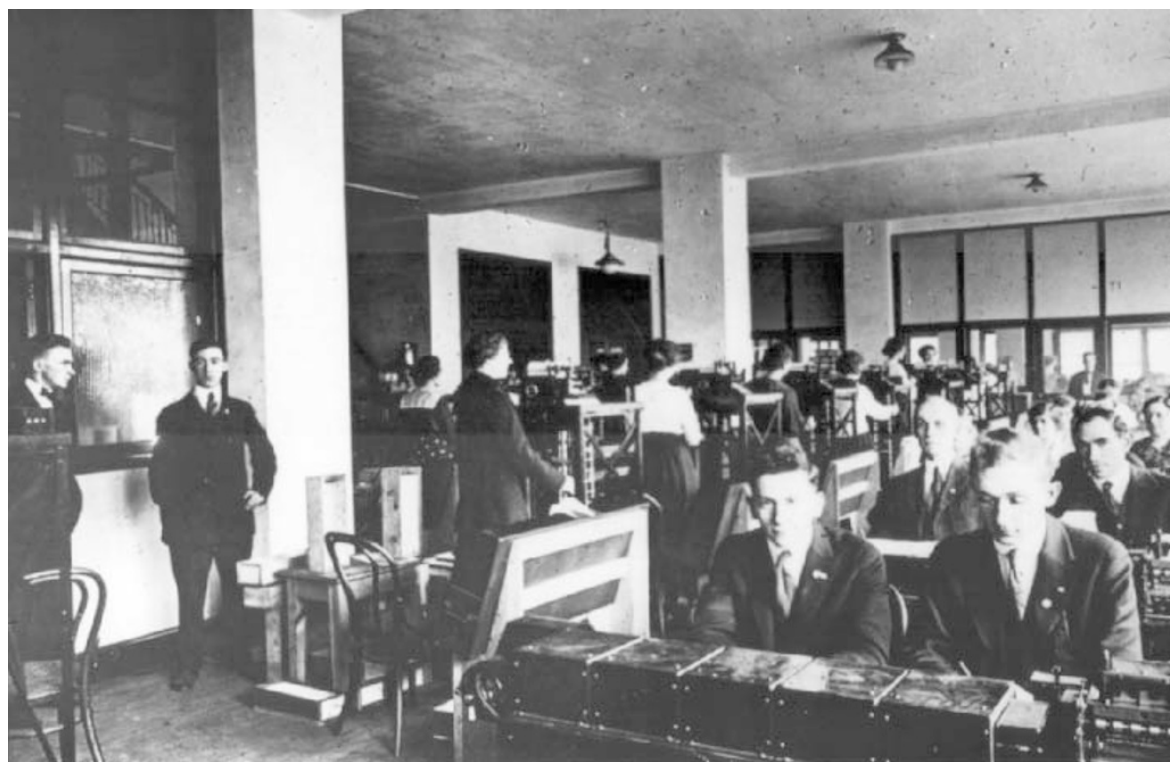

Crunch time: large numbers of people used to do the calculations now done by electronic computers.

\section{Recovered history}

When Computers Were Human

by David Alan Grier

Princeton University Press: 2005. 412 pp.

$\$ 35, £ 22.95$

\section{Jon Agar}

We work from morn till night,

For computing is ourduty;

We're faithful and polite,

And our record book's a beauty;

With Crelle and Gauss, Chauvenet and Peirce,

We labor hard all day;

We add, subtract, multiply and divide,

And we never have time to play.

(from The Observatory Pinafore by Winslow Upton, 1879)

Human computers certainly did work hard all day, and had the aches and pains to show for it: elbow joints inflamed from cranking calculator handles, or fingers and thumbs cramped from pencilling figure after figure on to graph paper. For two centuries the modern scientific enterprise was built on their efforts. Yet every time a logarithm was looked up, or the value of a Bessel function checked, a debt was incurred that was rarely acknowledged. And now the human computer has vanished from history.

People do not disappear from our collective memory by accident. Forgetting is not a passive process: people are forgotten for a reason. Two decades ago, the sociologist Steven Shapin noted pointedly that the lab technician, although essential to making an experiment work, rarely appeared in accounts of successful scientific work. But if something went wrong, the finger was pointed at human interference. Erasing the human hand was part of the means by which an experiment was seen to reveal aspects of nature, rather than aspects of society.

David Alan Grier's recovery of the wonderfully rich story of human computers not only allows us to repay a debt, but also to ask why human computers were made to disappear in the first place. They were drawn from the margins of the scientific establishment. Many were women. Nicole-Reine Lepaute, for example, the well-to-do wife of a royal clockmaker, was one of a trio - said to be the first astronomers to divide the labour of scientific calculation - who calculated the orbit of Halley's comet in time for its perihelion of 1758. Many later female computers came from much poorer backgrounds.

Male computers, too, were relatively disadvantaged. Many of the computers employed in Gaspard de Prony's Bureau du Cadastre, a factory of calculation, were hairdressers and wigmakers who had fallen on hard times following the French Revolution. Often the reason was financial: women, boys and immigrants made for cheap and willing labour. It was even said of Harvard Observatory, run by the relatively progressive Edward C. Pickering and staffed by college graduates, that the "computers are largely women who can be got to work for next to nothing".

By the Second World War, the heyday of human computers, they were routinely referred to as 'girls'. Indeed, managers calculated 'girl-years' of effort, and even defined the 'kilogirl', a unit for measuring work. But, as Grier emphasizes, "even at this date, computing was not the sole domain of women. It was really the job of the dispossessed, the opportunity granted to those who lacked the financial or societal standing to pursue a scientific career." For computing offered people from the margins an entry into the scientific world - an opportunity that they often grasped with both hands.

It is notoriously difficult to recover details 
of the lives of ordinary people: they rarely leave their words for posterity, and can be glimpsed only through the writings of their social superiors. Many more words have been written about Napoleon than about his foot soldiers. Indeed, it would take the imaginative power of a Tolstoy to reach back and reanimate the human computers labouring in the calculating offices of the eighteenth and nineteenth centuries. Despite Grier's industry, many still remain anonymous.

But Grier triumphantly achieves his aim when discussing the twentieth-century human computer, as many are alive to tell their tales. Take, for example, the life of Gertrude Blanch. Born Gittel Kaimowitz in Poland, and educated well, she fled the pogroms with her family. In the United States,

Theatre

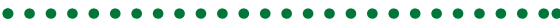
Artistic differences

\section{Phallacy}

written by Carl Djerassi

Performed at the New End Theatre, London, until 14 May 2005

\section{Robin Clark}

Phallacy is an intriguing play, well acted, fast moving and embracing a host of questions and human situations that are rarely touched upon in modern theatre. It was written by the distinguished synthetic chemist Carl Djerassi, who is best known for his role in the creation of the contraceptive pill. In recent years, Djerassi has turned his attention to writing scientifically based plays, including Calculus and (with Roald Hoffmann) Oxygen. Phallacy derives not only from his interests in science, but also from those as an art collector, and raises questions that arise at the interface of the arts and the sciences.

The play is based on the actual case of a revered life-sized bronze of a young man held in the Kunsthistorisches Museum, Vienna. It had been considered for several centuries to be a Roman original, its image even appearing on an Austrian postage stamp. However, scientific analysis in 1986 - specifically, thermoluminescence studies - revealed it to be a Renaissance cast. In Djerassi's play, this result opens the door to questions about how an object is devalued in such circumstances (really a question to do with market forces) and, more importantly, to a clash between professional reputations in the arts and the sciences.

The key players in this clash are a leading art historian, Regina Leitner-Opfermann
Gertrude struggled for years to find employment that matched her mathematical ability. But a chance meeting in 1937 with the director of the Mathematical Tables Project, Arnold Lowan, who shared her background, presented her with an opportunity that she gladly grasped. By 1940, the project was the largest scientific computing organization in the United States, and Blanch was one of its organizers. Grier traces in detail how Blanch's later career was blighted by the FBI's suspicions that she was a communist sympathizer.

Blanch's story is told with Grier's characteristic verve. But why did she, and her fellow human computers, disappear from history? Partly it was a familiar case of science erasing the traces of its human creation. But also

(convincingly played by Karen Archer), and a professor of chemistry, Rex Stolzfuss (played equally well by Jack Klaff), who had been invited to date the statue scientifically. She has written a 345-page book on the statue, describing every art-historical aspect of it in great detail. But her book lacks reference to any scientific analysis that might have a bearing on whether or not the statue dates to the correct period; the word 'thermoluminescence' doesn't even appear in the index.

The art historian — supposedly in search of 'artistic truth' - is a 'true believer', and can see her work and reputation being undermined by the chemist, who is concerned with the human computers suffered from the need to provide their successor with a suitable genealogy. At the seminal Moore School summer classes, where the team that built the ENIAC (the Electronic Numerical Integrator and Computer) spoke of new stored-program computers, listeners "heard a somewhat fanciful history of calculating devices that ignored the contributions of [human] computers". This "was an attempt to build a distinguished lineage for the electronic computing machine, a pedigree that ignored the influence of commerce and the hard labour of human computers."

Left undisturbed, victors write history. Jon Agar is in the Department of History and Philosophy of Science, University of Cambridge, Cambridge CB2 3RH, UK.

been insufficient communication. There is no 'artistic truth' or 'scientific truth' as such, but a presumed universal truth that requires for its establishment much more communication between the arts and sciences than is currently the case. It is certainly the scientists who are making the running here: many do read arts literature, whereas it is rare for art historians to read scientific literature, even that bearing upon art and artefacts.

Djerassi neatly highlights the importance of, and urgent need for, the scientific investigation of works of art. Such studies have recently called into question a host of heavily entrenched opinions that lack

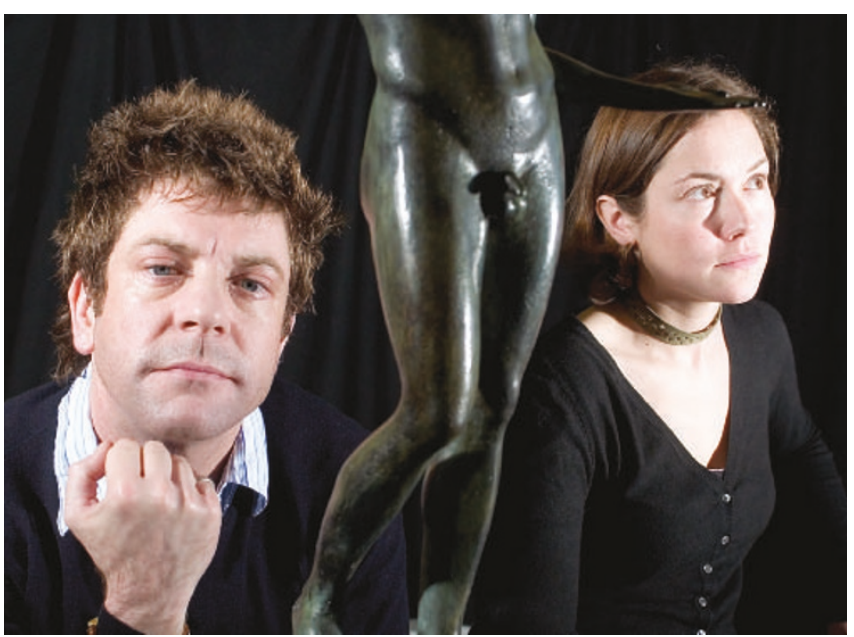

Supporting cast: Hamish Clark (left) and Lucy Liemann play figures on either side of a debate about the origins of a bronze in the play Phallacy. scientific credibility - notably concerning the Turin Shroud, the Vinland Map and certain Vermeer paintings.

A speculative sub-plot as to the likely provenance of the statue adds colour and entertainment value to the play without really impinging upon the main plot and debate. Such sub-plots are less appropriate in documentarytype productions of real cases of art evaluation, such as Nova Productions' The Viking Deception, which was recently shown on US television and in which I was interviewed about the analysis of the ink used on the Vinland Map. Much unnecessary space was devoted to the question of who might have drawn the Vinland

the facts, the scientific truth of the situation. $\mathrm{He}$ is in no doubt as to the correctness of his conclusions, which point to the statue being a sixteenth-century cast of hollowed bronze, which has a different trace metal content from that of Roman bronze and contains a far higher percentage of nickel.

The play is presented as a clash between incompatible cultures. I see instead a clash of the reputations of people working in different disciplines between which there has
Map, given that it wasn't the Vikings.

The supporting cast of Phallacy were excellent, notably the art historian's assistant Emma Finger (played by Lucy Liemann) and the professor's assistant Otto Ellenbogen (Hamish Clark). They all contributed to an appealing and thought-provoking new production.

Robin Clark is at Christopher Ingold Laboratories, University College London, 20 Gordon Street,

London WC1H OAJ, UK. 